\title{
Nye internasjonale retningslinjer for antitrombotisk behandling ved atrieflimmer
}

\author{
Sammendrag \\ Bakgrunn. De internasjonale retnings- \\ linjene for antitrombotisk behandling \\ ved atrieflimmer er nylig revidert. Dette \\ kan få betydning for klinisk praksis \\ i Norge.
}

\begin{abstract}
Materiale og metode. Nylig reviderte retningslinjer for antitrombotisk behandling ved atrieflimmer fra American College of Cardiology/American Heart Association/European Society of Cardiology og American College of Chest Physicians samt relevant annen litteratur gjennomgås og betydningen for norske forhold diskuteres.
\end{abstract}

Resultater. Flere studier tyder på at risikoen for hjerneslag ved atrieflimmer kan være noe lavere enn tidligere antatt. Dette er det tatt hensyn til i de nye internasjonale retningslinjene. CHADS2-skåren fremheves i disse som verktøy for å bestemme hvilke atrieflimmerpasienter som bør behandles med warfarin. Pasientene gis poeng etter enkle kliniske variabler - hjertesvikt: 1 poeng, hypertensjon: 1 poeng, alder over 75 år: 1 poeng, diabetes: 1 poeng, tidligere hjerneslag eller transitorisk iskemisk attakk (TIA): 2 poeng. Ved en CHADS2-skår på 0 poeng anbefales acetylsalisylsyre, ved 1 poeng warfarin eller acetylsalisylsyre, ved $\geq 2$ poeng anbefales warfarin.

Fortolkning. De nye internasjonale retningslinjene innebærer endringer i retning av høyere terskel for å gi warfarin til atrieflimmerpasienter. CHADS2skåren, som er basert på enkle kliniske karakteristika hos pasientene, har vist seg pålitelig og kan bidra til riktigere antitrombotisk behandling ved atrieflimmer.

\section{Arnljot Tveit}

arnljot.tveit@sabhf.no

Seksjon for indremedisinsk forskning

Medisinsk avdeling

Sykehuset Asker og Bærum

1309 Rud

Antikoagulasjonsbehandling med warfarin har meget god forebyggende effekt mot tromboembolisk hjerneslag hos pasienter med atrieflimmer (1). Tidligere så man i mange land et betydelig underforbruk av warfarin hos pasienter med atrieflimmer og høy risiko for hjerneslag, men dette synes å være bedret i de senere år (2-4). På den annen side har det også vært tendens til overbruk av warfarin hos lavrisikopasienter (2). En stor studie med pasienter $>75$ år med atrieflimmer viste at warfarinbehandling med INR-mål 2,5 er trygt og effektivt også i den eldste aldersgruppen, der man finner de fleste høyrisikopasientene (5).

Høsten 2006 offentliggjorde American College of Cardiology (ACC), American Heart Association (AHA) og European Society of Cardiology (ESC) reviderte felles retningslinjer for behandling av pasienter med atrieflimmer (6). Disse retningslinjene innebærer en noe strengere indikasjon for behandling med warfarin enn tidligere. Bakgrunnen for dette var at nyere studier tyder på at risikoen for hjerneslag ved atrieflimmer kan være noe lavere nå enn før $(7,8)$. Både disse retningslinjene og særlig de nylig publiserte anbefalingene fra American College of Chest Physicians (ACCP) legger vekt på den såkalte CHADS2-skåren som den beste til å avgjøre hvilke atrieflimmerpasienter som bør behandles med warfarin (9). Det gis poeng etter enkle kliniske variabler - hjertesvikt: 1 poeng, hypertensjon: 1 poeng, alder over 75 år: 1 poeng, diabetes: 1 poeng, tidligere hjerneslag eller transitorisk iskemisk attakk (TIA): 2 poeng. Ved en CHADS2-skår på 0 poeng anbefales acetylsalisylsyre, ved en skår på 1 poeng warfarin eller acetylsalisylsyre, ved en skår på $\geq 2$ poeng anbefales warfarin.

I denne artikkelen gjennomgås hovedtrekkene $i$ de nye anbefalingene, bakgrunnen for dem og hvilken betydning de kan få for klinisk praksis i Norge.

\section{Materiale og metode}

Innholdet i denne artikkelen tar utgangspunkt i kapitlet om antitrombotisk behandling i ACC/AHA/ESC 2006 guidelines for the management of patients with atrial fibrillation (6) og de nylig publiserte Antithrombotic therapy in atrial fibrillation: evidence-based clinical practice guidelines fra American College of Chest Physicians (9). For øvrig er det gjort et ikke-systematisk litteratursøk i PubMed, og artiklene er valgt ut på skjønn med bakgrunn i forfatterens erfaring innen feltet. Forfatteren har fra 2001 vært faglig ansvarlig for Atrieflimmerpoliklinikken og Tromboseklinikken (antikoagulasjonspoliklinikken) ved Sykehuset Asker og Bærum.

\section{CHADS2-skår}

Den såkalte CHADS2-skåren ble utviklet som hjelp i risikostratifiseringen av atrieflimmerpasienter (7). Den er senere validert og står sterkere enn andre risikostratifiseringsskjemaer (10). CHADS2-skåren er basert på enkle kliniske variabler og gjør at man i de fleste tilfeller kan gi pasienten et godt begrunnet råd om antitrombotisk behandling uten at det krever spesialiserte hjerteundersøkelser. CHADS2-skår står for følgende: congestive heart failure (hjertesvikt, enten ved klinisk erkjent stuvningssvikt eller ekkokardiografisk påvist redusert venstre ventrikkel-funksjon), hypertension (hypertensjon, ikke entydig definert, men oppfattes av de fleste som enten medikamentelt behandlet hypertensjon eller indikasjon for å behandle - det vil si gjentatte målinger over 140/90 mm Hg), age (alder over 75 år), diabetes og stroke (tidligere tromboembolisk hjerneslag eller TIA). De fire første tilleggsrisikofaktorene gir 1 poeng hver, mens tidligere tromboembolisk hjerneslag eller TIA gir 2 poeng (tab 1). Beregnet omtrentlig risiko for hjerneslag uten antitrombotisk behandling ut fra CHADS2-skår er presentert i tabell 2 (7). Både de data som la grunnlaget for CHADS2-skåren og andre studier tyder på at risikoen for hjerneslag

\section{Hovedbudskap}

- Nye internasjonale retningslinjer innebærer en noe høyere terskel for å anbefale warfarin til atrieflimmerpasienter enn tidligere

- CHADS2-skåren er basert på enkle kliniske karakteristika og kan brukes som rettesnor for valg av antitrombotisk behandling ved atrieflimmer 
ved atrieflimmer nå er lavere enn før, men dette gjelder muligens ikke dem som tidligere har hatt hjerneslag eller TIA $(7,11,12)$. Svært forenklet fremstilt: Man kan regne med at atrieflimmerpasienter under behandling med acetylsalisylsyre har en årlig risiko for hjerneslag på omkring $1 \%$ ved en CHADS2-skår på 0 og en risiko på $2 \%$ ved en CHADS2-skår på 1. Tilsvarende risiko for dem med en CHADS2-skår på 2 ligger på omkring $4 \%$, og risikoen øker med økende skår (10).

\section{Antitrombotisk behandling ved atrieflimmer}

Selv om en rekke nye antitrombotiske midler (særlig hemmere av trombin og faktor $\mathrm{Xa)}$ som alternativ til warfarin er under utvikling, står warfarin fortsatt $i$ en særstilling som det mest effektive midlet mot hjerneslag ved atrieflimmer. En relativt fersk metaanalyse bekrefter tidligere data som tyder på at warfarinbehandling reduserer risikoen for hjerneslag med $67 \%$ (1). I tillegg til redusert risiko for hjerneslag ser det ut til at atrieflimmerpasienter som får hjerneslag under warfarinbehandling får mindre sekvele enn dem som får acetylsalisylsyre eller ingen antitrombotisk behandling (13).

Acetylsalisylsyre gir en reduksjon i risikoen for hjerneslag på omkring $21 \%$. Det er usikkert om dette skyldes lavere embolirisiko eller bare er en effekt på aterotrombotiske slag, slik man ser i andre pasientgrupper (1). Nytt i de reviderte internasjonale retningslinjene er at man anbefaler acetylsalisylsyre i doser på ned til 75 mg daglig (9).

\section{Hovedtrekk i de nye internasjonale retningslinjene}

Både retningslinjene fra $\mathrm{ACC} / \mathrm{AHA} / \mathrm{ESC}$, utgitt i 2006, og de nylig utgitte retningslinjene fra ACCP baserer seg i stor grad på CHADS2-skåring $\mathrm{i}$ risikostratifiseringen ved atrieflimmer $(6,9)$. Anbefalingene er oppsummert i ramme 1.

Ved atrieflimmer og en CHADS2-skår på 0 anbefales ikke warfarin, fordi de som faller i denne kategorien har så lav risiko for hjerneslag at nytten av warfarinbehandling trolig ikke oppveier blødningsrisikoen. Verdt å merke seg er at atrieflimmerpasienter $i$ alderen 65-75 år etter disse retningslinjene ikke skal behandles med warfarin dersom de ikke har tilleggsrisikofaktorer. Dette står i kontrast til tidligere retningslinjer, både internasjonale og nasjonale, der det var en aldersgrense på 65 år $(14,15)$. Koronarsykdom er heller ikke med som tilleggsrisikofaktor i CHADS2-skåren. Det kan dels skyldes at langt bedre behandling i de senere år har gjort at denne tilstanden generelt er forbundet med lavere risiko for tromboemboliske hendelser. I 2006-retningslinjene fra ACC/ AHA/ESC heter det imidlertid at man kan vurdere warfarinbehandling også ved dårligere validerte tilleggsrisikofaktorer som koronarsykdom, alder 65-75 år og/eller hun- kjønn, mens dette ikke er nevnt i retningslinjene fra ACCP fra 2008.

Ved en CHADS2-skår på 1 kan man ifølge de nye retningslinjene gi enten acetylsalisylsyre eller warfarin. ACCP-retningslinjene anbefaler imidlertid at man i utgangspunktet bør foretrekke warfarin, fordi det er mest effektivt. Ved en CHADS2-skår på 2 eller mer anbefales warfarinbehandling.

Relativt ferske, store studier har understreket viktigheten av at det er tilstedeværelsen at tilleggsrisikofaktorer som avgjør om pasienten skal anbefales warfarin eller acetylsalisylsyre, ikke tidsforløpet av arytmien. En stor studie der man sammenliknet frekvenskontroll og rytmekontroll som behandlingsstrategi ved atrieflimmer, viste at hos pasienter som man antok var reetablert $i$ sinusrytme, var risikoen for hjerneslag uendret (16). Dette kan skyldes at mange har asymptomatiske atrieflimmerepisoder, langvarig svekket kontraksjonskraft $i$ atriene etter normalisering av hjerterytmen og muligens at atrieflimmer i seg selv kan være en markør for hjerneslagsrisiko ikke bare forårsaket av embolier fra venstre atrium. Det understrekes derfor sterkt at anfallsvis atrieflimmer skal vurderes på linje med vedvarende atrieflimmer når det gjelder valg av antitrombotisk behandling.

\section{Elektrisk og medikamentell konvertering}

Konvertering av atrieflimmer eller atrieflutter medfører risiko for hjerneslag etter prosedyren, uansett om denne gjøres medikamentelt eller elektrisk $(9,17)$. Risikoen for hjerneslag er høyest de første ti dager etter konvertering, det skyldes trolig en kombinasjon av forbigående svekket kontraksjonskraft i atriene og koagulasjonsaktivering (18).

På denne bakgrunn står det i de internasjonale retningslinjene at pasienter som skal til planlagt elektrisk eller medikamentell konvertering av atrieflimmer av $>48$ timers varighet, skal forbehandles med warfarin, med INR-mål 2,5 $(2,0-3,0)$, i minst tre uker før elektrokonvertering $(6,9)$. De fleste oppfatter dette slik at INR-verdien skal være 2,0 eller høyere i de siste tre uker før konverteringen, og mange bruker INR-mål 3,0 $(2,5-3,5)$ for å unngå et utilsiktet fall i INRverdien til under 2,0 og dermed utsettelse av prosedyren. Etter konverteringen gis warfarin i minst fire uker. Mange velger å gi mer langvarig behandling - for eksempel i tre måneder - fordi residivrisikoen er høy. Ved en CHADS2-skår på 2 eller mer bør i utgangspunktet warfarinbehandlingen fortsette på ubestemt tid uavhengig av om sinusrytme synes gjenopprettet. Hvis man likevel velger å stanse behandlingen, bør dette begrunnes i journalen.

Bruk av oesophagusekkokardiografi for å utelukke trombe og spontan ekkokontrast $i$ venstre forkammer benyttes ved mange sentre ved atrieflimmer av $>48$ timers varig-
Tabell 1 CHADS2-skår. Pasienter med atrieflimmer tildeles poeng for de angitte tilleggsrisikofaktorer, og summen av poeng utgjør CHADS2-skåren

\begin{tabular}{lc} 
Tilleggsrisikofaktor & Poeng \\
\hline Hjertesvikt & 1 \\
\hline Hypertensjon & 1 \\
\hline Alder $>75$ år & 1 \\
\hline Diabetes & 1 \\
\hline $\begin{array}{l}\text { Tidligere hjerneslag } \\
\text { eller TIA }\end{array}$ & 2 \\
\hline
\end{tabular}

Tabell 2 Beregnet årlig risiko for hjerneslag ut fra CHADS2-skår (7)

\begin{tabular}{cc} 
CHADS2-skår & Årlig risiko $(\%)$ \\
\hline 0 & 1,9 \\
\hline 1 & 2,8 \\
2 & 4,0 \\
\hline 3 & 5,9 \\
\hline 4 & 8,5 \\
\hline 5 & 12,5 \\
\hline 6 & 18,2 \\
\hline
\end{tabular}

het. Det gis da heparin (i Norge brukes lavmolekylært heparin) i terapeutiske doser før, under og etter konvertering inntil terapeutisk INR-nivå er nådd (19).

Ved atrieflimmer som man med rimelig sikkerhet vet har vart $<48$ timer, er det fortsatt akseptert å gjøre konverteringsforsøk uten forutgående antikoagulasjonsbehandling. Dette er mest basert på klinisk erfaring og i liten grad på vitenskapelige data, og til tross for at det er flere holdepunkter for at det kan dannes tromber i venstre atrium før det er gått 48 timer. Mange velger å gi lavmolekylært heparin (dalteparin $100 \mathrm{E} / \mathrm{kg}$ eller enoksaparin $1 \mathrm{mg} / \mathrm{kg}$ to ganger daglig) i forbindelse med prosedyren og fortsetter med dette til INR-nivået er $\geq 2,0$ hvis det startes warfarinbehandling. I retningslinjene fra ACCP anbefales rutinemessig bruk av heparin/lavmolekylært heparin ved konvertering av atrieflimmer av $<48$ timers varighet, mens retningslinjene fra ACC/AHA/ ESC anbefaler individuell vurdering på dette punkt. Ved en CHADS2-skår på $\geq 2$ bør man starte behandling med warfarin og fortsette med dette uavhengig av om stabil sinusrytme synes gjenopprettet. Ved en CHADS2-skår på 0 er start av warfarinbehandling $\mathrm{i}$ denne situasjonen neppe regningssvarende, individuell vurdering foreslås ved en CHADS2-skår på 1 .

Til pasienter med atrieflimmer av mer enn 48 timers varighet eller usikker varighet der konvertering vurderes som nødvendig på grunn av hemodynamisk ustabil situasjon anbefales lavmolekylært heparin i terapeutiske doser, som gis til warfarinbehandling er etablert med et INR-nivå $\geq 2,0$. 


\section{Ramme 1}

\section{Anbefalinger for bruk av antitrombotisk behandling ved atrieflimmer basert} på nye internasjonale retningslinjer (INR = internasjonalt normalisert ratio) $(6,9)$

Generelle retningslinjer

- Ved en CHADS2-skår på $\geq 2$ poeng anbefales warfarin med INR-mål 2,5 $(2,0-3,0)$

- Ved en CHADS2-skår på 1 poeng anbefales warfarin med INR-mål 2,5 (2,0-3,0) eller acetylsalisylsyre 75 (75-325) mg daglig

Ved en CHADS2-skår på 0 poeng anbefales acetylsalisylsyre 75 (75-325) mg daglig.

Anbefalingene gjelder uavhengig av om arytmien er anfallsvis eller vedvarende

Samme anbefalinger gjelder for atrieflutter

Elektrisk eller medikamentell konvertering

- Elektiv konvertering av atrieflimmer av > 48 timers varighet eller usikker varighet:

- Warfarin gis med INR-mål 2,5 $(2,0-3,0)$ i minst tre uker før konvertering. INR-verdier $<2,0$ i denne perioden bør unngås, og mange velger derfor et noe høyere INR-mål på 3,0 $(2,5-3,5)$

- Hvis oesophagusekkokardiografi utelukker atrial trombe, kan man alternativt gi dalteparin $100 \mathrm{E} / \mathrm{kg}$ eller enoksaparin $1 \mathrm{mg} / \mathrm{kg}$ to ganger daglig og gjøre konvertering uten forutgående warfarinbehandling. Dalteparin- eller enoksaparinbehandling fortsettes til INR-nivået er $\geq 2,0$

- Warfarin med INR-mål 2,5 (2,0-3,0) i minst fire uker etter konvertering. Ved en CHADS2skår på $\geq 2$ bør warfarinbehandlingen opprettholdes uavhengig av om stabil sinusrytme synes gjenopprettet

Ved konvertering av atrieflimmer som med rimelig sikkerhet har vart < 48 timer:

- Konvertering kan gjøres uten forutgående antikoagulasjonsbehandling

- Eventuelt gis dalteparin $100 \mathrm{E} / \mathrm{kg}$ eller enoksaparin $1 \mathrm{mg} / \mathrm{kg}$ to ganger daglig i forbindelse med prosedyren, som fortsettes til INR er $\geq 2,0$ hvis warfarinbehandling startes

- Ved en CHADS2-skår på $\geq 2$ bør warfarinbehandling startes og opprettholdes uavhengig av om stabil sinusrytme synes gjenopprettet. Ved en CHADS2-skår på 0 er oppstart av warfarin i denne situasjonen neppe regningssvarende. Individuell vurdering foreslås ved en CHADS2-skår på 1

Andre tilstander/prosedyrer

- Ved atrieflimmer og mekanisk hjerteventil anbefales som hovedregel warfarin med INRmål $3,0(2,5-3,5)$, alternativt $2,5(2,0-3,0)$ ved moderne aortaventil

Ved koronarsykdom og behov for perkutan koronar intervensjon hos pasient med atrieflimmer vil man normalt unngå medikamentavgivende stent. Etter prosedyren gis trippelbehandling med warfarin (INR-mål 2,2 (2,0-2,5)), acetylsalisylsyre 75 mg og klopidogrel $75 \mathrm{mg}$ daglig i fire uker, deretter kombinasjonsbehandling med warfarin og acetylsalisylsyre. Ved en CHADS2-skår på 0 kan man gi acetylsalisylsyre og klopidogrel uten warfarin I forbindelse med ablasjonsbehandling i venstre atrium mot atrieflimmer anbefales warfarin med INR-mål 2,5 (2,0-3,0) i minst 3-4 uker før og minst 2-3 måneder etter prosedyren. Ved en CHADS2-skår på $\geq 2$ bør warfarinbehandlingen opprettholdes uavhengig av om stabil sinusrytme synes gjenopprettet

\section{Andre tilstander/prosedyrer}

Mitralstenose er blitt relativt sjelden i Norge i våre dager, men forekomsten er høyere $\mathrm{i}$ andre land. Ved atrieflimmer og mitralstenose anbefales warfarinbehandling med INRmål 2,5 (2,0-3,0), uavhengig av CHADS2skår for øvrig. Ved atrieflimmer og mekanisk hjerteventil anbefales som hovedregel warfarin med INR-mål $3,0(2,5-3,5)$, alternativt $2,5(2,0-3,0)$ ved moderne aortaventil.

Behandlingen av koronarsykdom, særlig akutt hjerteinfarkt, er betydelig endret de seneste år og innebærer ofte perkutan koronar intervensjon med innlegging av stent. Dobbelt platehemmende behandling med acetylsalisylsyre og klopidogrel den første tiden etter intervensjonen er avgjørende for å holde det behandlede kar åpent. Dette gjelder særlig ved medikamentavgivende stenter, som endotelialiseres sent. Det er begrenset erfaring med kombinasjonen acetylsalisylsyre, klopidogrel og warfarin, men det er begrunnet mistanke om høyere blødningsrisiko ved slik behandling enn ved behandling med kombinasjonen acetylsalisylsyre og warfarin (20). Hos en pasient med atrieflimmer der det er indikasjon for warfarin, vil man derfor normalt unngå medikamentavgivende stent. Etter perkutan koronar intervensjon med innlegging av ren metallstent gis trippelbehandling med warfarin (INR-mål 2,2 (2,0-2,5), acetylsalisylsyre 75 $\mathrm{mg}$ og klopidogrel $75 \mathrm{mg}$ daglig i fire uker, deretter anbefales kombinasjonsbehandling med warfarin og acetylsalisylsyre (21). Internasjonalt mener mange at man i stedet bør foretrekke kombinasjonen warfarin og klopidogrel, selv om dette savner vitenskapelig dokumentasjon (6). Ved en CHADS2-skår på 0 kan det gis langvarig kombinasjonsbehandling med acetylsalisylsyre og klopidogrel (i Norge betyr det vanligvis ni måneder pga. refusjonsreglene) uten warfarin.

I forbindelse med ablasjonsbehandling i venstre atrium mot atrieflimmer anbefales warfarin med INR-mål 2,5 i minst 3-4 uker før og minst 2-3 måneder etter prosedyren $(22,23)$. Ved mange sentre anbefaler man rutinemessig seks måneders behandling med warfarin etter prosedyren, og ved en CHADS2-skår på $\geq 2$ bør man fortsette warfarinbehandlingen uavhengig av om stabil sinusrytme synes gjenopprettet, blant annet fordi mange har «stumme» episoder med atrieflimmer (22).

\section{Konsekvenser for klinisk praksis i Norge}

Vi bør også i Norge justere vår praksis i henhold til de nye internasjonale retningslinjene. Basert på CHADS2-algoritmen er ikke warfarin indisert ved en skår på 0 - det innebærer at de som er under 75 år og ellers friske ikke skal ha warfarin ved atrieflimmer. I Norge har det vært vanlig å starte warfarinbehandling hos atrieflimmerpasienter over 65 år, uavhengig av andre risikofaktorer. Denne praksisen bør nå revurderes. 2006anbefalingene fra ACC/AHA/ESC inneholder som nevnt et punkt der man angir det som rimelig å vurdere warfarin eller acetylsalisylsyre også for dem som er i alderen 65-75 år, av hunkjønn og/eller med koronarsykdom, men man presiserer at disse tilleggsrisikofaktorene er dårlig validert (6). De er utelatt både i de nye retningslinjene fra ACCP og i CHADS2-skåren (9). En mer detaljert CHADS2-skår, der det tas hensyn til kjønn og flere alderskategorier, er foreslått, men denne er mer komplisert i bruk (8).

Én ting er å vurdere oppstart av warfarinbehandling på basis av de nye retningslinjene, et annet spørsmål er hva man skal gjøre med pasienter med en CHADS2-skår på 0 som allerede får slik behandling. Hvis en pasient $\mathrm{i}$ denne kategorien skulle få en alvorlig blødning, har vedkommende kanskje grunn til å klage på at det ble gitt warfarinbehandling. Når det gjelder pasienter $\mathrm{i}$ alderen 65-75 år, av hunkjønn eller med koronarsykdom, vil man altså ha en viss ryggdekning for å gi warfarin i henhold til 2006-retningslinjene fra ACC/AHA/ESC, for de øvrige bør bruk av warfarin revurderes sammen med pasienten. Det er grunn til å tro at det er forskjell på å slutte med warfarin etter lengre tids stabil behandling og det å la være å starte warfarinbehandling. For det første er det grunn til å anta at veletablert, stabil warfarinbehandling er tryggere enn behandling i oppstartsfasen, som oftere innebærer blødningskomplikasjoner (24). For det andre er det visse holdepunkter for et «rebound-fenomen» ved warfarinstopp (25). Hos pasienter med en CHADS2-skår på 0 eller 1, som er negative til warfarinbehandling og/eller har vært vanskelige å regulere kan man med fordel revurdere behandlingen og benytte anledningen til å slutte med warfarin.

Ved en CHADS2-skår på 1 kan man ifølge de nye internasjonale retningslinjene velge enten acetylsalisylsyre eller warfarin. 
Valget bør baseres på individuell vurdering, der særlig pasientens preferanser, men også vedkommendes evne til å gjennomføre warfarinbehandling på adekvat måte og eventuell blødningsrisiko vektlegges. Det er spesielt viktig med god informasjon, slik at pasienten kan være med på å ta et begrunnet valg av medikament.

Pasienter $>75$ år med andre tilleggsrisikofaktorer ifølge CHADS2-skåren og dermed høy risiko for hjerneslag, bør få tilbud om warfarin. Flere store studier viser at warfarinbehandling er effektiv og sikker også i denne aldersgruppen når den blir riktig gjennomført, og at falltendens sjelden bør brukes som grunn til ikke å starte warfarinbehandling $(5,26)$.

\section{Konklusjon}

Ved atrieflimmer er risikostratifisering avgjørende for riktig valg av antitrombotisk behandling. Fortsatt er det mange pasienter med høy risiko for hjerneslag som ikke får warfarin, samtidig er det mange med lav risiko som behandles unødvendig. CHADS2-skåren er enkel å bruke og treffer godt når det gjelder hjerneslagsrisiko. Systematisk bruk av denne i risikostratifiseringen kan derfor gi bedre antitrombotisk behandling ved atrieflimmer.

Oppgitte interessekonflikter: Forfatteren har mottatt honorar for foredrag og/eller konsulentoppdrag for Nycomed Pharma, AstraZeneca, Sanofi Aventis og MSD innen fagfeltet antitrombotisk behandling ved atrieflimmer.

\section{Litteratur}

1. Hart RG, Pearce LA, Aguilar MI. Meta-analysis: antithrombotic therapy to prevent stroke in patients who have nonvalvular atrial fibrillation. Ann Intern Med 2007; 146: 857-67.

2. Nieuwlaat R, Capucci A, Lip GY et al. Antithrombotic treatment in real-life atrial fibrillation patients: a report from the Euro Heart Survey on Atrial Fibrillation. Eur Heart J 2006; 27: 3018-26.

3. Friberg J, Gislason GH, Gadsboll N et al. Temporal trends in the prescription of vitamin $\mathrm{K}$ antagonists in patients with atrial fibrillation. J Intern Med 2006: 259: 173-8.

4. Tveit A, Abdelnoor M, Enger $S$ et al. Atrial fibrillation and antithrombotic therapy in a 75-year-old population. Cardiology 2008; 109: 258-62.

5. Mant J. Hobbs FD. Fletcher K et al. Warfarin versus aspirin for stroke prevention in an elderly community population with atrial fibrillation lthe Birmingham Atrial Fibrillation Treatment of the Aged Study, BAFTA): a randomised controlled trial. Lancet 2007: 370: 493-503.

6. Fuster V, Ryden LE, Cannom DS et al. ACC/AHA/ ESC 2006 guidelines for the management of patients with atrial fibrillation: full text: a report of the American College of Cardiology/American Heart Association Task Force on practice guidelines and the European Society of Cardiology Com mittee for Practice Guidelines (Writing Committee to Revise the 2001 guidelines for the management of patients with atrial fibrillation] developed in collaboration with the European Heart Rhythm Association and the Heart Rhythm Society. Europace 2006; 8: $651-745$.

7. Gage BF, Waterman AD, Shannon W et al. Validation of clinical classification schemes for predicting stroke: results from the National Registry of Atrial Fibrillation. JAMA 2001; 285: 2864-70.

8. Rietbrock S, Heeley E, Plumb J et al. Chronic atrial fibrillation: Incidence, prevalence, and prediction of stroke using the Congestive heart failure, Hypertension, Age $>75$, Diabetes mellitus, and prior Stroke or transient ischemic attack
(CHADS2) risk stratification scheme. Am Heart 2008; 156: 57-64

9. Singer DE, Albers GW, Dalen JE et al. Antithrombotic therapy in atrial fibrillation: American College of Chest Physicians Evidence-Based Clinical Practice Guidelines (8th Edition). Chest 2008; 133 (suppl 6) : 546-92

10. Gage BF, van Walraven C, Pearce L et al. Selecting patients with atrial fibrillation for anticoagulation stroke risk stratification in patients taking aspirin. Circulation 2004; 110: 2287-92.

11. Go AS, Hylek EM, Chang Y et al. Anticoagulation therapy for stroke prevention in atrial fibrillation: how well do randomized trials translate into clinical practice? JAMA 2003; 290: 2685-92.

12. Albers GW, Diener HC. Frison L et al. Ximelagatran vs warfarin for stroke prevention in patients with nonvalvular atrial fibrillation: a randomized trial. JAMA 2005: 293. 690-8.

13. Hylek EM, Go AS, Chang Y et al. Effect of intensity of oral anticoagulation on stroke severity and mor tality in atrial fibrillation. N Engl J Med 2003; 349: 1019-26.

14. Fuster V, Ryden LE, Asinger RW et al. ACC/AHA ESC guidelines for the management of patients with atrial fibrillation. A report of the American College of Cardiology/American Heart Association Task Force on Practice Guidelines and the European Society of Cardiology Committee for Practice Guidelines and Policy Conferences (Committee to develop guidelines for the management of patients with atrial fibrillation) developed in collaboration with the North American Society of Pacing and Electrophysiology. Eur Heart J 2001; 22: 1852-923.

15. Reikvam A, Sandset PM. Warfarinbehandling i praksis - tryggere antikoagulasjon. Skriftserien for leger. Oslo: Den norske legeforening, 2005.

16. Wyse DG, Waldo AL, DiMarco JP et al. A comparison of rate control and rhythm control in patients with atrial fibrillation. N Engl J Med 2002; 347 1825-33.

17. Bjerkelund CJ, Orning OM. The efficacy of anticoagulant therapy in preventing embolism related to D.C. electrical conversion of atrial fibrillation. Am J Cardiol 1969; 23: 208-16

18. Gallagher MM, Hennessy BJ, Edvardsson N et al. Embolic complications of direct current cardioversion of atrial arrhythmias: association with low intensity of anticoagulation at the time of cardio version. J Am Coll Cardiol 2002: 40: 926-33.
19. Klein AL, Grimm RA, Murray RD et al. Use of transesophageal echocardiography to guide cardioversion in patients with atrial fibrillation. N Engl J Med 2001: 344: 1411-20.

20. Karjalainen PP. Porela P. Ylitalo A et al. Safety and efficacy of combined antiplatelet-warfarin therapy after coronary stenting. Eur Heart J 2007; 28: 726-32.

21. Becker RC, Meade TW, Berger PB et al. The primary and secondary prevention of coronary artery disease: American College of Chest Physicians Evidence-Based Clinical Practice Guidelines (8th Edition). Chest 2008; 133 (suppl 6): 776-814.

22. Calkins $\mathrm{H}$, Brugada J, Packer DL et al. HRS/EHRA/ ECAS expert consensus statement on catheter and surgical ablation of atrial fibrillation: recommendations for personnel, policy, procedures and follow-up. A report of the Heart Rhythm Society (HRS) Task Force on Catheter and Surgical Ablation of Atrial Fibrillation developed in partnership with the European Heart Rhythm Association (EHRA) and the European Cardiac Arrhythmia Society (ECAS); in collaboration with the American College of Cardiology (ACC), American Heart Association (AHA), and the Society of Thoracic Surgeons (STS). Endorsed and approved by the governing bodies of the American College of Cardiology, the American Heart Association, the European Cardiac Arrhythmia Society, the European Heart Rhythm Association, the Society of Thoracic Surgeons, and the Heart Rhythm Society. Europace 2007: 9: 335-79.

23. Blanc JJ, Almendral J Brignole M et al. Consensus document on antithrombotic therapy in the setting of electrophysiological procedures. Europace 2008; 10: 513-27.

24. Breen AB, Vaskinn TE, Reikvam A et al. Warfarinbehandling og blødninger. Tidsskr Nor Lægeforen 2003; 123: 1835-7.

25. Palareti G, Legnani C. Warfarin withdrawal. Pharmacokinetic-pharmacodynamic considerations. Clin Pharmacokinet 1996: 30:300-13.

26. Garwood CL, Corbett TL. Use of anticoagulation in elderly patients with atrial fibrillation who are at risk for falls. Ann Pharmacother 2008; 42: 523-32.

Manuskriptet ble mottatt 31.10. 2008 og godkjent 23.4. 2009. Medisinsk redaktør Åslaug Helland. 